\title{
Research on the Mechanism of Decompression and Augmented Injection during Waterflooding Development in Low Permeability Reservoirs
}

\author{
Zhang Shuo*, $^{* 1,2}$, Jiang Guan-Cheng ${ }^{1,2}$, Xie Shui-Xiang ${ }^{1,2}$ and Wang Le ${ }^{1,2}$ \\ ${ }^{1}$ State Key Laboratory of Petroleum Resource and Prospecting, China University of Petroleum, Beijing, China; ${ }^{2} \mathrm{MOE}$ \\ Key Laboratory of Petroleum Engineering, China University of Petroleum, Beijing 102249, China
}

\begin{abstract}
Developing low permeability reservoirs becomes more and more important to the sustainable energy development in China and the waterflooding development is the common mode. But with the oilfield development, water injection well has exposed some problems gradually, such as the injection pressure increases, water injection rate decreases and so on. Based on this situation, scale inhibitor, corrosion inhibitor and other additives are added in injection water continually, which increases the development cost to a large extent.

In order to develop low permeability reservoirs better and more economical, we proposed a novel decompression and augmented injection technology by manufacturing a novel surfactant FS-01, which could change the wettability of the rock surface and has the features of low free surface energy, low interfacial tension, emulsifying and so on. The decompression and augmented injection mechanism is discussed by measuring the contact angle, SEM (scanning electron microscope), EDX (energy dispersive X-ray), oil-water relative permeability test and so on. After the core surface treated by FS-01, the contact angle of crude oil and the core surface increases from $35.35^{\circ}$ to $85.7^{\circ}$, which has perfect wettability reversal function. After the successful application in well HJS112-21 in ShengLi oilfield, it is proved that the new technology has well decompression and augmented injection function.
\end{abstract}

Keywords: Waterflooding, decompression, augmented injection, surfactant, rock surface property, low permeability reservoir, wettability reversal, surfactant.

\section{INTRODUCTION}

Low and extra low permeability reservoirs are characterized by tiny pore throats, complicated structures, serious heterogeneity, large oil-water flow resistance and so on [1]. As the water flooding continues, the water injection well pressure increases quickly, water injection rate decreases and injection water is deficient, at the same time, hydration swelling happens, water blocking damage and jamin effect occur [2-4]. Conventional acidification deblocking measures do not have remarkable results, and the valid period is short (some valid periods of the water injection wells are just one month).

The main mechanism of waterflooding in low permeability reservoirs is the imbibition of water $[5,6]$. By changing the rock surface wettability, we could enhance the water phase permeability [7-9]. At present, the technology of decompression and augmented injection during the waterflooding development has been studied at home and abroad, at the same time, tests have been put on in some oilfields and acquire certain results [10-13]. But for the particularity of low reservoirs, conventional surfactants can not attain the aim of well decompression and augmented injection.

*Address correspondence to this author at the Department of Petroleum Engineering, China University of Petroleum, Beijing 102249, China;

Tel: 010-8973. 2239; E-mail: zhangshuo915@ sina.com
Based on the fact, we synthesize a novel surfactant FS-01 to change the wettability of low permeability reservoirs which could enhance the oleophobicity of the rock surface. In order to enhance the development in low permeability reservoirs, the decompression and augmented injection mechanism is studied. The surfactant could change the wettability of the rock surface, which could reduce the surface and interfacial tension, enhance the emulsifying ability and so on [14-17]. After the laboratory tests and field application, it is proved that the new surfactant could change the injection water property and rock surface wettability, which could attain the aim of well decompression and augmented injection.

\section{MATERIALS AND APPROACHES}

\subsection{Instruments and Reagent}

Spinning drop interfacial tensiometer, energy dispersive X-ray (EDX), Quanta 200F scanning electron microscopy (SEM), Three-neck flask, thermostatic water bath, contact angle measurement apparatus, shear mixer, Displacement experiment device.

Sulfobetaine type fluorocarbon surfactant (FS-01), perfluorooctanesulfonyl fluoride (PF), N,N-dimethyl-1,3propanediamine (NNDP), isopropyl ether (IE), N-perfluorinated sulfonamide (NFA), sodium 2-hydroxy-3-chloro propanesulfate (SHCP), distilled water, epichlorohydrin (EN), isopropanol (IL), Sodium bisulfite (SB), methanol. 


\subsection{Copolymer Synthesis}

\subsubsection{Synthesis Mechanism}

Non-polar groups of the common surfactants are C-H chains, but the Non-polar groups of the fluorocarbon surfactants are F-C chains. The fluorocarbon surfactants are the surfactant whose $\mathrm{C}-\mathrm{H}$ chains are replaced by F-C chains.

The bond energy of F-C chains is higher than that of C-H chains, so F-C chains are more stable than $\mathrm{C}-\mathrm{H}$ chains and harder to be polarized. The fluorocarbon surfactant FS-01 have stronger hydro-oleophobicity than common surfactants because of the lower polarity.

\subsubsection{Experimental Steps}

(1) The NNDP and IE are slowly added into a three-neck flask and the mixture is made to homogeneous emulsion, and then put the three-neck flask under water-bath of $10^{\circ} \mathrm{C}$. The PF solution is dropped into the three-neck flask slowly, and then ascend the temperature to $60^{\circ} \mathrm{C}$. Transfer the solution into the beaker after complete reaction, we would get the compound NFA and the chemical reaction equation is shown as follows:

$\mathrm{CF}_{3}-\left(\mathrm{CF}_{2}\right)_{7}-\mathrm{SO}_{2} \mathrm{~F}+\mathrm{H}_{2} \mathrm{~N}-\left(\mathrm{CH}_{2}\right)_{3} \mathrm{~N}-\mathrm{CH}_{3} \rightarrow \mathrm{CF}_{3}-\left(\mathrm{CF}_{2}\right)_{7}-\mathrm{SO}_{2}-\mathrm{NH}-\left(\mathrm{CH}_{2}\right)_{3} \mathrm{~N}-\mathrm{CH}_{3}+\mathrm{HF}$

(2) The SB and methanol are mixed and the mixture is made to homogeneous emulsion, and then the EN solution is dropped into the mixture. After the complete reaction under the condition of $85^{\circ} \mathrm{C}$, we would get the compound SHCP and the chemical reaction equation is shown as follows:<smiles>NS(=O)(=O)[C@@H]1OC1CCNCCC(O)CCl</smiles>

(3) The NFA and IL are slowly added into a three-neck flask at $60^{\circ} \mathrm{C}$, and then SHCP is dropped into the mixture. Ascend the temperature to $85^{\circ} \mathrm{C}$ and the reaction time is 6 hours, transfer the emulsion into a beaker and dry it. At last, we would get the novel fluorocarbon surfactant FS01 and the chemical reaction equation is shown as follows:

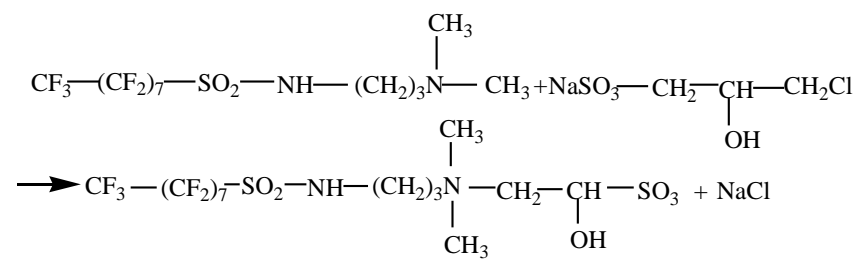

\subsection{Core Surface Properties}

\subsubsection{Wettability}

Clean and dry the natural core slice, then immerse it in FS-01 solution under different concentrations for hours and dried naturally. Measure the distilled water and oil contact angle respectively. The natural cores are derived from Shengli Oilfield HJS112-21 Well Shahejie strata (2589.53m 2667.28m).

\subsubsection{Surface Free Energy}

One end of the surfactant molecular is polar and the other end is non-polar. The water molecular has very strong polarity, and then the surfactant molecular will adsorb on the surface of the solution. As is shown in Fig. (1), the polar end of the surfactant molecular is toward water and the other end is toward oil or gas, which could decrease the oil-water interfacial tension. So the oil is washed from the rock surface more easily.
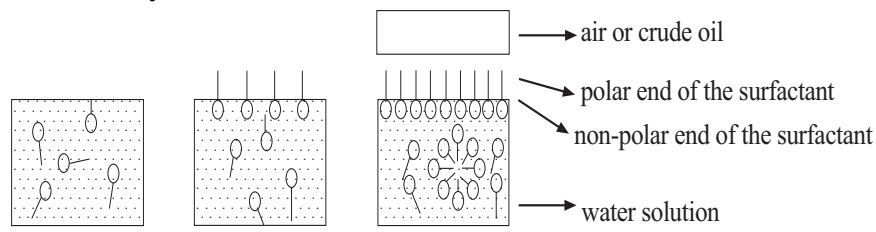

Fig. (1). Principle of low interfacial tension.

The solid surface free energy could be calculated with the Owens method, which needs two test reagents with known dispersion force and polar force. Distilled water and crude oil are chosen as test reagents. The dispersion force and polar force of distilled water are 21.8 and $51.0 \mathrm{~mJ} / \mathrm{m}^{2}$ respectively while those of oil are 27.6 and $0 \mathrm{~mJ} / \mathrm{m}^{2}$ respectively.

\subsubsection{SEM Analysis}

The natural core and the one treated by FS-01 are observed by Quanta 200F scanning electron microscopy and the energy spectrum is also analyzed.

\subsection{Emulsification}

As is shown in Fig. (2), the fluorocarbon surfactant will absorb at the water-oil interface, which will decrease the water-oil interfacial tension. The fluorocarbon surfactant could form stable oil-in-water emulsion and oil is hard to adhere to the rock surface during the waterflooding process.

Mix crude oil $(100 \mathrm{ml})$ with FS-01 solution under different concentrations, stir for 10 minutes at $25^{\circ} \mathrm{C}$ and observe the phenomenon.

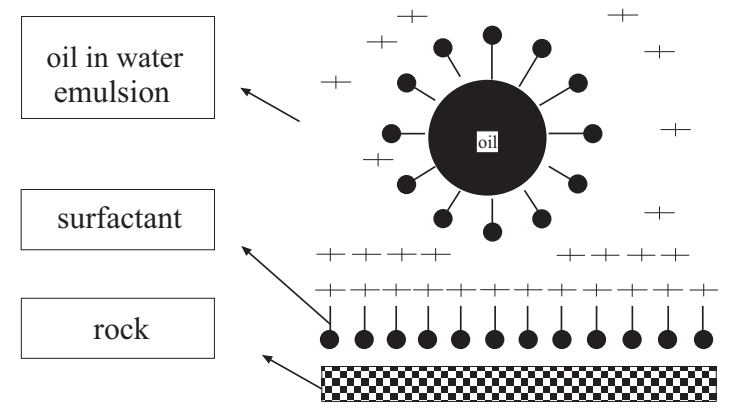

Fig. (2). Principle of emulsification.

\subsection{Oil-water Relative Permeability}

Oil-water relative permeability tests are taken by the distilled water and FS-01 solution (5\%) respectively.

\subsection{Oil Recovery Efficiency and Injection Pressure}

Two oil saturated cores are displaced by the distilled water and FS-01 solution (5\%), the recovery efficiency and injection pressure are measured.

\section{RESULTS AND DISCUSSION}

\subsection{Wettability}

Figs. (3) and (4) indicate that the contact angles of the rock surface become bigger after the core treated by FS-01. 

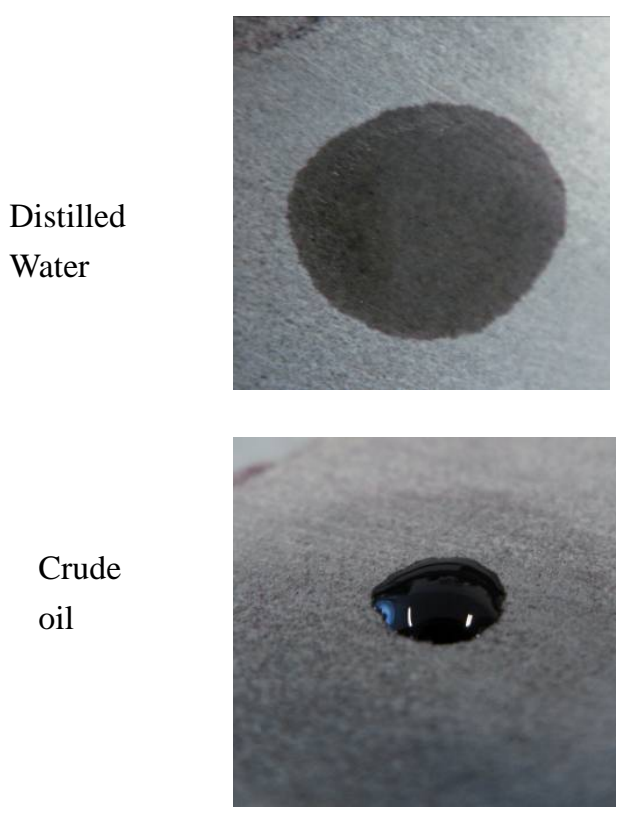

a. Untreated
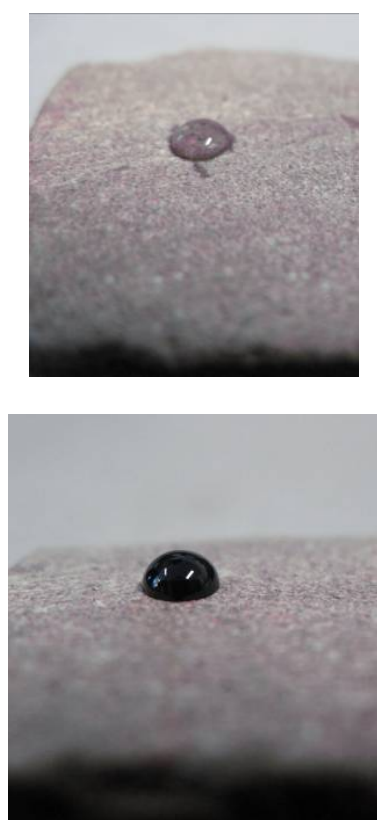

b. Treated
Fig. (3). Photos of the core slice.

The contact angle of water and the core surface increases from $2.2^{\circ}$ to $35.5^{\circ}$, the contact angle of crude oil and the core surface increases from $35.3^{\circ}$ to $85.7^{\circ}$. It is concluded that FS01 has quite well wettability reversal function which could increase the oleophobicity of the core surface by a large extent.



Fig. (4). Contact angle.

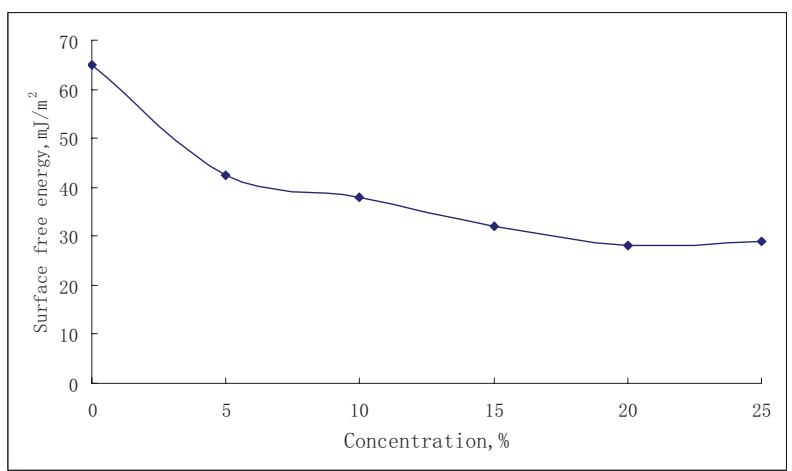

Fig. (5). Surface energy.

\subsection{Surface Free Energy}

Fig. (5) shows that, the surface free energy of core slices treated by FS-01 has a significant reducing trend as the concentration increases form 0 to $25 \%$. Surface free energy of the cores treated by FS-01 reduces from $65.2 \mathrm{~mJ} / \mathrm{m}^{2}$ to $9.25341 \mathrm{~mJ} / \mathrm{m}^{2}$, which are far lower than the surface tension of distilled water $(72.8 \mathrm{mN} / \mathrm{m})$ and general oils (25 to 35 $\mathrm{mN} / \mathrm{m}$ ), thus, the core surface is hard to be wetted by general fluids and shows the character of low energy.

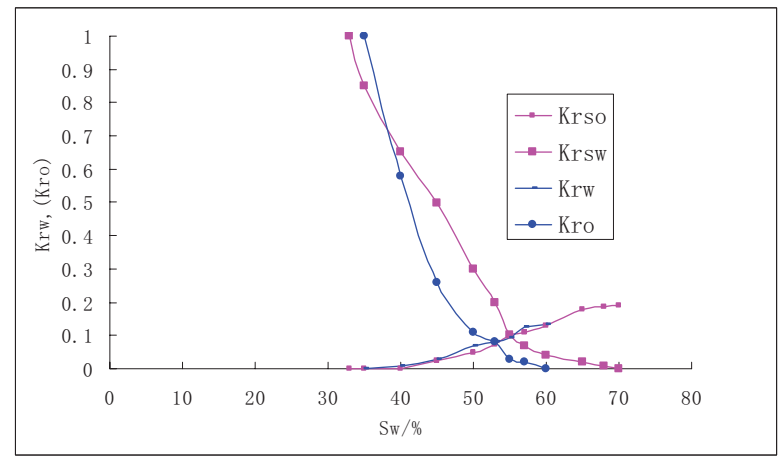

Fig. (6). Relative permeability.



Fig.(7). Oil recovery.

\subsection{Oil-water Relative Permeability}

Fig. (6) indicates the changes of the relative permeability. When the core is displaced by distilled water, the residual oil saturation is $40.6 \%$, the bound water saturation at the equivalent permeability point is $51.8 \%$ and the range of the 
Table 1. Results of the Emulsion Tests

\begin{tabular}{|c|c|c|c|c|c|}
\hline Sample NO. & $\mathbf{0}$ & $0.1 \%$ & $0.5 \%$ & $1.0 \%$ & $2.0 \%$ \\
\hline 1 & sharp interface & $\begin{array}{l}\text { Massive } \\
\text { fusion }\end{array}$ & $\begin{array}{l}\text { Massive } \\
\text { fusion }\end{array}$ & $\begin{array}{l}\text { Complete } \\
\text { fusion }\end{array}$ & $\begin{array}{l}\text { Complete } \\
\text { fusion }\end{array}$ \\
\hline 2 & sharp interface & $\begin{array}{l}\text { Massive } \\
\text { fusion }\end{array}$ & $\begin{array}{l}\text { Complete } \\
\text { fusion }\end{array}$ & $\begin{array}{l}\text { Complete } \\
\text { fusion }\end{array}$ & $\begin{array}{l}\text { Complete } \\
\text { fusion }\end{array}$ \\
\hline 3 & sharp interface & $\begin{array}{l}\text { Partial } \\
\text { fusion }\end{array}$ & $\begin{array}{l}\text { Complete } \\
\text { fusion }\end{array}$ & $\begin{array}{l}\text { Complete } \\
\text { fusion }\end{array}$ & $\begin{array}{l}\text { Complete } \\
\text { fusion }\end{array}$ \\
\hline 4 & sharp interface & $\begin{array}{l}\text { Partial } \\
\text { fusion }\end{array}$ & $\begin{array}{l}\text { Massive } \\
\text { fusion }\end{array}$ & $\begin{array}{l}\text { Complete } \\
\text { fusion }\end{array}$ & $\begin{array}{l}\text { Complete } \\
\text { fusion }\end{array}$ \\
\hline
\end{tabular}

oil water two-phase flow is narrow. When the core is displaced by FS-01 solution, the residual oil saturation is $31.4 \%$, the bound water saturation at the equivalent permeability point is $55.1 \%$ and the range of the oil water two-phase flow is broader than the one displaced by distilled water. The oil-water equivalent permeability point moves to the right, which proves that the water phase relative penetration has improved and the wettability of the rock is reversed to the hydrophilicity. After the test it is proved that FS-01 could improve the water phase penetration and the water absorbing ability of the core.

\subsection{Emulsion Test}

We could see that FS-01 solution has well emulsifying capacity on crude oil from Table 1 . When the concentration of FS-01 reaches $0.1 \%$, partial or massive fusion happens. The concentration reaches $1.0 \%$, the FS-01 solution and the oil is on the state of complete fusion. It is proved that FS-01 has perfect emulsifying capacity which is good for oil migration.

\subsection{Oil Recovery Efficiency and Injection Pressure}

Fig. (7) indicates that the oil recovery efficiency (displaced by FS-01) is higher than the one (displaced by distilled

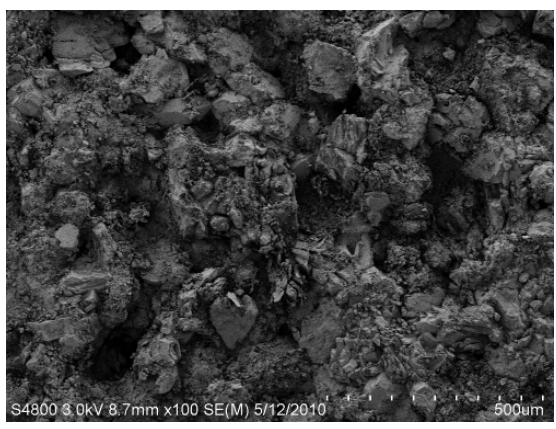

A. Untreated

\begin{tabular}{|l|l|l|}
\hline Element & Wt\% & At \% \\
\hline F K & 0.85 & 1.21 \\
\hline Si K & 48.95 & 44.13 \\
\hline
\end{tabular}

water) by $15.06 \%$. The injection pressure decreases from $7.68 \mathrm{MPa}$ to $5.66 \mathrm{MPa}$ and the pressure-drop rate is $26.3 \%$. The distinction becomes conspicuous after 4 hours because adequate adsorption of FS-01 needs a period of time. The adsorption of FS-01 could improve the oil recovery efficiency and decrease the injection pressure.

\subsection{SEM}

Fig. (8) indicates that the natural core surface is mainly composed of big particles and pores, the main element of the untreated core is silicon, and the quality percentage of silicon is $48.95 \%$ while fluorine is only $0.85 \%$.

After the core surface treated by FS- 01 solution, the core surface particles become smaller and the porosity decreases. The quality percentage of silicon decreases to $41.96 \%$, while fluorine increases to $9.74 \%$, which indicated that FS-01 had adsorbed on the core surface.

\section{FIELD APPLICATION}

We had the field application in ShengLi Oilfield HJS11221 Well. The reservoir porosity distributes from $11.6 \%$ to $21.4 \%$, the average porosity is $18.2 \%$. The reservoir permeability distributes from $1.9 \times 10^{-3} \mu^{2}$ to $26.4 \times 10^{-3} \mu^{2}$, the average permeability is $9.2 \times 10^{-3} \mu \mathrm{m}^{2}$. We could see that

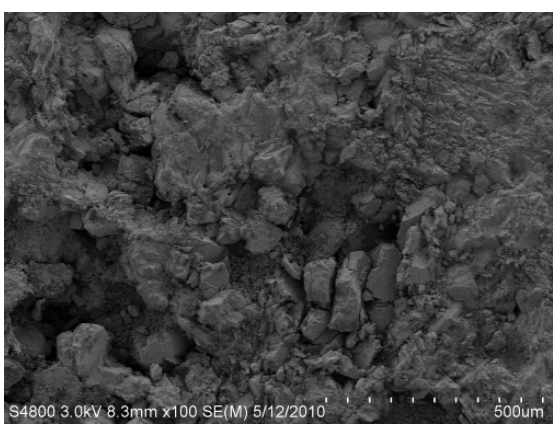

B. Treated

\begin{tabular}{|l|l|l|}
\hline Element & Wt\% & At\% \\
\hline F K & 9.74 & 12.36 \\
\hline Si K & 41.96 & 40.21 \\
\hline
\end{tabular}

Fig. (8). SEM of core surface. 
the reservoir has the feature of low porosity and low permeability, FS-01 solution (3\%) is injected from the injection string in the field application.

By using the technology, the injection pressure reduced from 20.9 MPa to $15.2 \mathrm{MPa}$ and daily water-injection rate increased from $4.5 \mathrm{~m}^{3} / \mathrm{d}$ to $8.7 \mathrm{~m}^{3} / \mathrm{d}$. The valid period is more than half a year and the developing cost is reduced by $25.5 \%$. It is demonstrated that the new fluorocarbon surfactant FS-01 has made a great effort in decompression and augmented injection during the waterflooding development in low permeability reservoirs.

\section{CONCLUSION}

1. The wettability is reversed to water-wet largely after the adsorption of FS-01 on the rock surface, contact angles of distilled water and crude oil increase to $35.5^{\circ}$ and $85.7^{\circ}$ respectively.

2. The technology could decrease the surface free energy and the interfacial tension, the surface free energy decreases to $8.25341 \mathrm{~mJ} / \mathrm{m}^{2}$. After the emulsion, oilwater relative permeability and oil recovery efficiency test, it is demonstrated that the technology could enhance the oil recovery efficiency, water phase penetration and the water absorbing ability.

3. After the field application, it is proved that the new technology is competent for decompression and augmented injection during the waterflooding development in low permeability reservoirs.

\section{NOMENCLATURE}

$$
\begin{aligned}
& S_{w} \quad=\text { The bound water saturation, } \% \\
& K_{r s o} \quad=\text { The oil phase relative penetration } \\
& \text { (displaced by FS-01) } \\
& K_{r s w} \quad=\text { The water phase relative penetration } \\
& \text { (displaced by FS-01) } \\
& K_{r w} \quad=\text { The water phase relative penetration } \\
& \text { (displaced by distilled water) } \\
& K_{r o} \quad=\text { The oil phase relative penetration } \\
& \text { (displaced by distilled water) }
\end{aligned}
$$

\section{CONFLICT OF INTEREST}

None declared.

\section{ACKNOWLEDGEMENTS}

This work is supported by the National Science Fund for Distinguished Young Scholars (Project NO. 50925414) and the National Science and Technology Major Project (Project NO. 2011ZX05009-005-03A).

\section{REFERENCES}

[1] Q.M. Wang, and Q. Wang, "Low permeability reservoir percolation rules and waterflooding mechanism testing", Journal of Jianghan Petroleum Institute, vol. 25, pp. 102-103, 2003.

[2] O.D. Adeniyi, J.U. Nwalor, and C.T. Ako, "A review on waterflooding problems in Nigeria's crude oil production", Journal of Dispersion Science and Technology, vol. 29, no. 3, pp.362-365, 2008.

[3] X. Zhang, and Y.Q. Bi, "Research on activity of water increase injection technique in low permeability", Petroleum Geology and Engineering, vol. 11, no. 12, pp. 2804-2806, 2011.

[4] O.D. Adeniyi, J.U. Nwalor, and C.T. Ako, "A review on waterflooding problems in Nigeria's oil production", Journal of Dispersion Science and Technology, vol. 29, no. 3, pp. 362-365, 2008.

[5] Y.D. Yao, J.L. Ge, and J.Z. Wei, "Study on the fluid flow in low permeability reservoir", Petroleum Exploration and Development, vol. 23, no. 5, pp. 121-124, 2009.

[6] S.Y. Qiu, J.M. Chen, and H. Tang, "EOR through depressurization and augmented injection with surfactant", Henan Petroleum, vol. 19 , no. 6, pp. 52-54, 2005.

[7] C.M. Xiao, "Effect of oil components on interfacial tension of surfactants in chemical flooding", Special Oil \& Gas Reservoirs, vol. 18 , no. 3, pp. 66-69, 2011.

[8] J.X. Guo, and X.H. Gao, "The optimization for surfactant oil displacement system in low permeability reservoirs", Applied Chemical Industry, vol. 40, no. 6, pp. 940-945, 2011.

[9] J.C. Wu, Z.Q. Jia, and L.R. Sun, "Analysis of mechanisms of lowering trigger pressure of extra low permeability reservoirs", Journal of DaQing Petroleum Institute, vol. 27, no. 2, pp. 83-85, 2003.

[10] M.P. Shahri, S.R. Shadizadeh, and M. Jamialahmadi, "applicability test of new surfactant produced from zizyphus spina-christi leave for enhanced oil recovery in carbonate reservoirs", Journal of The Japan Petroleum Institute, vol. 55, no.1, pp. 27-32, 2012.

[11] B.Y. Jamaloei, "Chemical flooding in naturally fractured reservoirs: fundamental aspects and field-scale practices", Oil \& Gas Science and Technology-Revue D IFP Energies Nouvelles, vol. 66, no. 6, pp. 991-1004, 2011.

[12] W.M. Stoll, H. Shureqi, and J. Finol, "Alkaline/surfactant/polymer flood: from the laboratory to the field", SPE Reservoir Evaluation \& Engineering, vol. 14, no. 6, pp. 702-712, 2011.

[13] K. Zhang, and J.S. Qin, "The Effect of alkali and surfactant on polymer molecular structure", Petroleum Science and Technology, vol. 29, no. 2, pp. 183-191, 2011.

[14] Z.X. Pang, H.Q. Liu, and X.L. Liu, "Characteristics of formation damage and variations of reservoir properties during steam injection in heavy oil reservoir", Petroleum Science and Technology, vol. 28, no. 5, pp. 477-493, 2010.

[15] Z.C. Bi, L.Y. Qi, and W.S. Liao, "Dynamic surface properties, wettability and mimic oil recovery of ethanediyl-alpha (cetyldimethylammonium bromide) on dodecane modified silica powder", Journal of Materials Science, vol. 40, no. 11, pp. 2783$2788,2005$.

[16] A.L. Ogunberu, and M. Ayub, "The role of wettability in petroleum recovery", Petroleum Science and Technology, vol. 23, no. 2, pp. 169-188, 2005.

[17] M. Robin, "Interfacial phenomena: Reservoir wettability in oil recovery", Oil \& Gas Science and Technology Y-Revue De L Institut Francais Du Petrole, vol. 56, no. 1, pp. 55-62, 2001. 